\title{
PENGETAHUAN TANDA BAHAYA KEHAMILAN DAN PERILAKU PERAWATAN KEHAMILAN PADA IBU HAMIL TRIMESTER III
}

\author{
Fandiar Nur Isdiaty*, Titin Ungsianik \\ Fakultas Ilmu Keperawatan, Universitas Indonesia, Depok 16424, Indonesia \\ *E-mail: fandiarnurisdiaty@gmail.com
}

\begin{abstract}
Abstrak
Salah satu penyebab tingginya angka kematian ibu adalah komplikasi kehamilan yang dapat muncul melalui tanda bahaya kehamilan. Pengetahuan ibu hamil dalam mengenali tanda bahaya dapat menjadi salah satu penentu perawatan kehamilan untuk mencegah komplikasi. Penelitian ini bertujuan untuk mengetahui hubungan antara pengetahuan tanda bahaya kehamilan dengan perilaku perawatan kehamilan pada ibu hamil trimester III. Penelitian ini menggunakan desain deskriptif korelatif dengan pendekatan cross sectional. Pengambilan sampel menggunakan teknik consecutive sampling dengan responden penelitian berjumlah $96 \mathrm{ibu}$ hamil trimester III yang sedang melakukan kunjungan antenatal care di Puskesmas Cimanggis dan Puskesmas Sukmajaya. Hasil penelitian menunjukkan tidak ada hubungan yang signifikan secara statistik antara pengetahuan tanda bahaya kehamilan dengan perilaku perawatan kehamilan pada ibu hamil trimester III $(\mathrm{p}=0,135 ; \alpha=0,05)$. Peneliti memberikan rekomendasi kepada petugas kesehatan agar lebih memotivasi ibu hamil untuk merawat kehamilan dengan baik.
\end{abstract}

Kata kunci: kehamilan, pengetahuan, perawatan kehamilan, tanda bahaya kehamilan

\begin{abstract}
Knowledge of Obstetric Danger Signs and Pregnancy Caring Behaviors among Third Semester Pregnant Women. Obstetric complications have been known as one of the causes of high maternal mortality rate. Women knowledge in recognizing danger signs can be one of the determinations of pregnancy caring behaviors in preventing further complications. This study aimed to determine the relationship between knowledge of obstetric danger signs and pregnancy care behavior among third trimester pregnant women. This study applied a descriptive correlative design with cross sectional approach. Consecutive sampling used as sampling technique. Samples of this study were 96 third trimester pregnant women who attended antenatal care in two community health care centers. This study showed that there was no statistically significant relationship between knowledge of obstetric danger signs and pregnancy care behaviors among third trimester pregnant women $(p=0.135 ; \alpha=0.05)$. This study recommends that health care professional should motivate pregnant women to take a care of their pregnancy.
\end{abstract}

Keywords: knowledge, obstetric danger signs, pregnancy, pregnancy care behavior

\section{Pendahuluan}

Angka Kematian Ibu (AKI) yang dihitung per 100.000 kelahiran di Indonesia masih menunjukkan penurunan yang lambat. Berdasarkan hasil Survei Demografi dan Kesehatan Indonesia (SDKI), pada tahun 1991 AKI mencapai 390 jiwa, tahun 1997 mencapai 334 jiwa, tahun 2003 mencapai 307 jiwa dan pada tahun 2007 AKI mencapai 228 jiwa. Menurut Badan Perencanaan dan Pembangunan Nasional (2010) angka tersebut akan terus diupayakan menurun menjadi 102 jiwa pada tahun 2015 seperti yang tertuang dalam target Millenium Development Goals (MDGs). Sementara itu, kematian ibu di kota Depok mencapai 17 jiwa pada tahun 2008 (Dinas Kesehatan Kota Depok, 2008).

Penyebab kematian maternal antara lain perdarahan $(25 \%)$, infeksi $(15 \%)$, aborsi yang tidak aman (13\%), eklampsia (12\%), persalinan yang buruk $(8 \%)$, penyebab obstetrik langsung lainnya (8\%), dan penyebab tidak langsung (20\%) (WHO, 2005). Beberapa penyebab 
kematian maternal tersebut disebabkan adanya komplikasi yang dapat muncul melalui tanda bahaya kehamilan.

Morbiditas dan mortalitas ibu hamil dapat dicegah apabila ibu hamil dan keluarganya mampu mengenali tanda bahaya kehamilan dan mencoba untuk mencari pertolongan kesehatan (Hailu, Gebremariam, \& Alemseged, 2010). Tanda bahaya kehamilan yang dapat muncul antara lain perdarahan vagina, edema pada wajah dan tangan, demam tinggi, ruptur membran, penurunan pergerakan janin, dan muntah persisten (Chapman \& Durham, 2010; Pillitteri, 2010). Menurut Rashad dan Essa (2010) tindakan yang tepat dapat menghindarkan ibu hamil dari penyebab kematian maternal yang dapat dicegah. Tindakan dalam bentuk perawatan kehamilan yang dapat dilakukan dapat berupa antenatal care, menjaga kebersihan diri, memenuhi kebutuhan nutrisi, melakukan aktivitas fisik dan aktivitas seksual sewajarnya, tidur dan istirahat yang cukup, dan lain sebagainya (Bobak, Lowdermilk, \& Jensen, 1995/2005; Pillitteri, 2010).

Penelitian mengenai pengetahuan tanda bahaya kehamilan telah banyak dilakukan, sedangkan penelitian mengenai perilaku perawatan kehamilan secara holistik masih belum banyak dilakukan. Sebagian besar penelitian menyatakan respondennya memiliki pengetahuan yang rendah dalam menyebutkan tanda-tanda bahaya kehamilan (Pembe et al., 2009; Kabakyenga et al., 2011; dan Hailu, et al, 2010). Penelitian Panthumas, et al. (2012) yang dilakukan pada 206 remaja primigravida di Thailand menyatakan bahwa perilaku perawatan diri mereka selama hamil kurang tepat.

Perubahan perilaku pada seseorang dapat diawali dari adanya stimulus pengetahuan (Notoatmodjo, 2007). Seseorang yang telah mendapatkan stimulus pengetahuan idealnya akan membentuk sikap dan perilaku yang saling bersesuaian. Sampai saat ini belum banyak penelitian mengenai hubungan pengetahuan tanda bahaya kehamilan dan perilaku perawatan kehamilan secara holistik di Indonesia. Oleh karena itu penelitian ini bertujuan untuk mengetahui hubungan pengetahuan tanda bahaya kehamilan dengan perilaku perawatan kehamilan pada ibu hamil trimester III.

\section{Metode}

Penelitian deskriptif korelatif ini menggunakan pendekatan cross sectional dengan teknik sampling consecutive sampling. Sampel berjumlah $96 \mathrm{ibu}$ hamil trimester III yang melakukan pemeriksaan kehamilan di Puskesmas Cimanggis dan Puskesmas Sukmajaya. Kuesioner terstruktur yang dikembangkan peneliti terdiri dari tiga bagian antara lain karakteristik responden meliputi usia ibu hamil, pendidikan, pekerjaan, usia kehamilan dan graviditas; pengetahuan tanda bahaya kehamilan; dan perilaku perawatan kehamilan.

Selanjutnya data diolah melalui tahapan editing, coding, processing, dan cleaning dengan menggunakan software pengolah data. Analisis data menggunakan analisis univariat dan bivariat. Analisis bivariat menggunakan analisis chi square dengan kemaknaan 0,05. Kategori pengetahuan dan perilaku menggunakan cut off point mean karena data berdistribusi normal (Hastono, 2006). Peneliti memperhatikan etika penelitian. Etika penelitian tersebut antara lain anonymity \& confidentiality, protection from discomfort \& harm, informed consent, dan self determination.

\section{Hasil}

Karakteristik Responden. Sebagian besar responden berada pada tahap dewasa awal dengan rentang usia 21-40 tahun $(90,6 \%)$. Mayoritas responden tidak bekerja $(85,4 \%)$ dengan pendidikan terakhir terbanyak adalah SMA $(60,4 \%)$. Responden terbanyak primigravida $(68,8 \%)$ dengan rerata usia kehamilan 33,36 minggu, usia kehamilan termuda adalah 27 minggu dan usia kehamilan tertua 41 minggu.

Pengetahuan Tanda Bahaya Kehamilan. Mayoritas responden memiliki pengetahuan yang tinggi terhadap tanda bahaya kehamilan. 
Dari tujuh komponen pengetahuan mengenai tanda bahaya kehamilan, konsep tanda bahaya kehamilan dan perdarahan vagina adalah komponen pengetahuan yang banyak dimiliki responden. Komponen pengetahuan rendah yang paling banyak dimiliki oleh responden adalah edema dan muntah persisten.

Perilaku Perawatan Kehamilan. Hasil penelitian menunjukkan perbedaan yang tipis pada kategori perilaku. Namun demikian dari hasil penelitian dapat disimpulkan bahwa perilaku yang kurang tepat adalah perilaku yang paling banyak dimiliki responden. Dari enam komponen perilaku perawatan kehamilan, pemeriksaan kehamilan dan pemenuhan kebutuhan nutrisi adalah perilaku yang banyak dilakukan oleh responden dengan tepat. Sementara perilaku yang kurang tepat banyak dimiliki responden mengenai kebersihan badan secara umum.
Hubungan Pengetahuan Tanda Bahaya Kehamilan dengan Perilaku Perawatan Kehamilan pada Ibu Hamil Trimester I. Ibu hamil yang mempunyai pengetahuan rendah menunjukkan perilaku yang tepat dalam perawatan kehamilan yaitu sebanyak $38,5 \%$. Sedangkan pada ibu hamil yang mempunyai pengetahuan tinggi menunjukkan perilaku yang tepat dalam perawatan kehamilan yaitu sebanyak 56,1\%. Berdasarkan pada hasil uji bivariat dapat disimpulkan bahwa tidak ada hubungan yang signifikan secara statistik antara pengetahuan tanda bahaya kehamilan dengan perilaku perawatan kehamilan pada ibu hamil trimester III ( $p=0,135, \alpha=0,05)$. Berdasarkan hasil pada Tabel 1 terlihat nilai $\mathrm{OR}=2,048$, artinya ibu hamil yang memiliki pengetahuan tinggi memiliki peluang 2,048 kali untuk berperilaku dengan tepat dalam merawat kehamilan.

Tabel 1. Pengetahuan dan Komponen Tanda Bahaya Kehamilan

\begin{tabular}{lcccc}
\hline \multirow{2}{*}{\multicolumn{1}{c}{ Variabel }} & \multicolumn{3}{c}{ Kategori } \\
\cline { 2 - 5 } & \multicolumn{2}{c}{ Tinggi } & Rendah \\
\cline { 2 - 5 } \multicolumn{1}{c}{ Pengetahuan Tanda Bahaya } & $\mathbf{N}$ & $\mathbf{N}$ & \% \\
\hline Komponen Pengetahuan & 57 & 59,4 & 39 & 40,6 \\
Konsep Tanda Bahaya & & & & \\
Perdarahan Vagina & 91 & 94,8 & 5 & 5,2 \\
Edema & 90 & 93,8 & 6 & 6,3 \\
Demam Tinggi & 33 & 34,4 & 63 & 65,6 \\
Penurunan Gerak Janin & 50 & 52,1 & 46 & 47,9 \\
Muntah Persisten & 59 & 61,5 & 37 & 38,5 \\
Ruptur Membran & 37 & 38,5 & 59 & 61,5 \\
\hline
\end{tabular}

Tabel 2. Perilaku dan Komponen Perawatan Kehamilan

\begin{tabular}{|c|c|c|c|c|}
\hline \multirow{3}{*}{ Variabel } & \multicolumn{4}{|c|}{ Kategori } \\
\hline & \multicolumn{2}{|c|}{ Tepat } & \multicolumn{2}{|c|}{ Kurang Tepat } \\
\hline & $\mathbf{N}$ & $\%$ & $\mathbf{n}$ & $\%$ \\
\hline Perilaku Perawatan Kehamilan & 47 & 49 & 49 & 51 \\
\hline \multicolumn{5}{|l|}{ Komponen Perilaku } \\
\hline Kebersihan Badan Secara Umum & 28 & 29,2 & 68 & 70,8 \\
\hline Tidur \& Istirahat & 57 & 59,4 & 39 & 40,6 \\
\hline Aktivitas Seksual & 48 & 50 & 48 & 50 \\
\hline Pemeriksaan Kehamilan & 60 & 62,5 & 36 & 37,5 \\
\hline Aktivitas Fisik & 48 & 50 & 48 & 50 \\
\hline Nutrisi & 59 & 61,5 & 37 & 38,5 \\
\hline
\end{tabular}


Tabel 3. Hubungan Pengetahuan Tanda Bahaya Kehamilan dengan Perilaku Perawatan Kehamilan pada Ibu Hamil Trimester III

\begin{tabular}{|c|c|c|c|c|c|}
\hline \multirow{2}{*}{$\begin{array}{c}\text { Pengetahuan Tanda Bahaya } \\
\text { Kehamilan } \\
\end{array}$} & \multicolumn{2}{|c|}{ Perilaku Perawatan Kehamilan } & \multirow{2}{*}{ Total } & \multirow{2}{*}{$\begin{array}{c}\text { OR } \\
(95 \% \mathrm{CI}) \\
\end{array}$} & \multirow[b]{2}{*}{$p$} \\
\hline & Perilaku Kurang Tepat & Perilaku Tepat & & & \\
\hline Pengetahuan Rendah & $24(61,5 \%)$ & $15(38,5 \%)$ & $39(100 \%)$ & 2,048 & 0,135 \\
\hline Pengetahuan Tinggi & $25(43,9 \%)$ & $32(56,1 \%)$ & $57(100 \%)$ & $(0,9-4,7)$ & \\
\hline
\end{tabular}

\section{Pembahasan}

\section{Pengetahuan Tanda Bahaya Kehamilan.} Mayoritas responden memiliki pengetahuan yang tinggi. Hasil penelitian ini sejalan dengan penelitian Rashad dan Essa (2010) yang dilakukan pada ibu hamil di daerah Mesir dengan proporsi pengetahuan yang cukup dan baik sebesar 73,6\%. Dalam penelitiannya Rashad dan Essa juga menyimpulkan bahwa tingkat pendidikan memiliki hubungan yang signifikan dengan kewaspadaan tanda bahaya kehamilan.

Hasil penelitian ini tidak sejalan dengan penelitian yang dilakukan di Ethiophia oleh Hailu, et al. (2010) yang menunjukkan hanya $30,4 \%$ responden yang berpengetahuan tinggi. Penelitian lain yang dilakukan di Uganda oleh Kabakyenga, et al. (2011) menunjukkan hal yang sama di mana hanya sebanyak 19\% responden yang mampu menyebutkan minimal tiga tanda bahaya kehamilan. Hal ini dapat dianalisis berdasarkan karakteristik pendidikan dimana mayoritas responden pada kedua penelitian tersebut berpendidikan rendah bahkan tidak dapat membaca dan menulis (Hailu, et al., 2010).

Pengetahuan tanda bahaya kehamilan dinilai melalui beberapa komponen antara lain konsep tanda bahaya, perdarahan vagina, edema, demam tinggi, penurunan gerak janin, muntah persisten, dan ruptur membran (Chapman \& Durham, 2010; Pillitteri, 2010). Ibu hamil perlu mengetahui tanda bahaya kehamilan karena munculnya tanda bahaya dapat menjadi indikasi adanya kemungkinan bahaya pada kehamilan yang dapat berdampak buruk pada kesehatan ibu hamil dan janin (Littleton \& Engebretson, 2009; Pillitteri, 2010).
Hasil penelitian menunjukkan hampir seluruh responden mempunyai pengetahuan yang tinggi mengenai konsep tanda bahaya kehamilan dan perdarahan vagina diikuti secara berurutan oleh ruptur membran, penurunan gerak janin, dan demam tinggi. Sedangkan pengetahuan rendah yang banyak dimiliki oleh responden adalah mengenai edema dan diikuti oleh muntah persisten.

Perdarahan vagina perlu diketahui oleh banyak ibu hamil karena kematian maternal sebanyak $25 \%$ disebabkan oleh perdarahan vagina (WHO, 2005). Selain itu edema pada wajah, jari, tangan, dan kaki yang terus-menerus dapat menjadi indikasi preeklamsia yang dapat berlanjut menjadi eklamsia apabila disertai kejang-kejang. Menurut WHO (2005) eklamsia menyebabkan kematian maternal sebanyak 12\% (WHO, 2005).

Perilaku Perawatan Kehamilan. Hasil penelitian menunjukkan sebagian besar responden memiliki perilaku yang kurang tepat dalam perawatan kehamilan. Hasil penelitian ini sejalan dengan penelitian yang dilakukan oleh Panthumas, et al. (2012) pada 206 remaja primigravida di Thailand yang menunjukkan lebih banyak responden yang memiliki perilaku kurang tepat dalam merawat kehamilan. Praktik perawatan kehamilan sangat penting dilakukan karena menurut penelitian Sulistiyowati, Ronoatmodjo, dan Tarigan (2001), praktik perawatan kehamilan yang tidak adekuat meningkatkan risiko 2,3 kali kematian perinatal.

Perilaku perawatan kehamilan yang dilakukan mulai dari seorang wanita terdiagnosa hamil sampai sesaat sebelum janin lahir, dinilai melalui beberapa komponen antara lain kebersihan 
badan secara umum, tidur dan istirahat, aktivitas seksual, pemeriksaan kehamilan, aktivitas fisik, dan pemenuhan kebutuhan nutrisi. Hasil penelitian menunjukkan perilaku perawatan yang tepat banyak dimiliki oleh responden mengenai pemeriksaan kehamilan dan pemenuhan kebutuhan nutrisi, selanjutnya diikuti oleh tidur dan istirahat. Perilaku kurang tepat yang banyak dimiliki responden adalah kebersihan badan secara umum. Sedangkan komponen aktivitas seksual dan aktivitas fisik memiliki proporsi yang sama antara perilaku yang tepat dan perilaku yang kurang tepat.

Pemeriksaan kehamilan penting dilakukan untuk memantau kesehatan ibu dan janin. Hasil penelitian ini sejalan dengan penelitian Celik dan Hotchkiss (2000) di mana sebagian besar respondennya menunjukkan perilaku baik dalam melakukan antenatal care pada tenaga kesehatan. Sedangkan pemenuhan kebutuhan nutrisi sejalan dengan hasil penelitian Mawaddah dan Hardinsyah (2008) yang menyatakan bahwa sebagian besar respondennya memiliki perilaku baik dalam praktik pemenuhan gizi.

Kenyamanan ibu hamil adalah aspek penting yang perlu diperhatikan. Untuk meningkatkan kenyamanan selama hamil, ibu hamil dianjurkan untuk menjaga kebersihan badan meliputi mandi, merawat gigi dan payudara serta berpakaian longgar (Pilitteri, 2010). Ibu hamil cenderung mengeluarkan lebih banyak keringat sehingga mandi minimal dua kali sehari sangat dianjurkan untuk dilakukan oleh ibu hamil.

Hasil analisis menunjukkan tidak ada hubungan yang signifikan secara statistik antara pengetahuan tanda bahaya kehamilan dengan perilaku perawatan kehamilan pada ibu hamil trimester III. Meskipun demikian, dapat dilihat pada tabel bahwa ibu hamil yang berpengetahuan tinggi memiliki peluang 2,048 kali untuk memiliki perilaku yang tepat dalam perawatan kehamilan.

Hasil penelitian ini dapat dijelaskan melalui teori Rogers (1974) dalam Notoatmodjo (2007) di mana untuk mengadopsi perilaku tertentu, seseorang perlu melalui beberapa tahapan. Seseorang yang sudah tahu dan sadar terhadap adanya stimulus tanda bahaya kehamilan belum tentu akan berperilaku yang benar sampai ia melewati beberapa tahap hingga akhirnya mengadopsi suatu perilaku yang baik dalam hal ini perilaku merawat kehamilan.

Adanya pengetahuan dan informasi yang membuat seseorang sampai pada tahap tahu dan sadar saja belum cukup dalam mempengaruhi perubahan perilaku seseorang (Herbert, 1996). Pernyataan tersebut didukung oleh pernyataan Coates (1988), O'Keeffe (1990), Page (1985) dalam Cole, Holtgrave, dan Rios (n.d) yang menyatakan bahwa pengetahuan dan informasi saja belum cukup untuk menurunkan adanya perilaku yang berisiko sehingga perlu adanya dorongan dan dukungan dari sosial terhadap seseorang untuk mengubah perilaku agar dapat diaplikasikan secara berkelanjutan. Hal inilah yang menunjukkan bahwa perilaku dalam merawat kehamilan dapat disebabkan oleh banyak variabel yang juga berhubungan signifikan secara statistik.

Green dalam Notoatmodjo (2007) menyebutkan bahwa perilaku seseorang didasari oleh beberapa faktor seperti faktor predisposisi, faktor pendukung, dan faktor pendorong. Faktor predisposisi contohnya adalah nilai dan budaya yang dapat mempengaruhi perawatan kehamilan salah satunya pantangan terhadap makanan tertentu (Suryawati, 2007). Fasilitas kesehatan sebagai faktor pendukung juga dapat mempengaruhi perawatan kehamilan khususnya dalam melakukan antenatal care (Kristina, 2009). Sedangkan faktor pendorong misalnya dorongan dan dukungan dari pasangan. Penelitian Martin, et al. (2007) menunjukkan bahwa dukungan sosial mempengaruhi kunjungan prenatal care dan penurunan jumlah konsumsi rokok oleh ibu hamil selama mereka hamil.

Penelitian Panthumas, et al. (2012) dan Sen, et al. (2012) menyatakan bahwa terdapat faktorfaktor yang dapat mempengaruhi perilaku perawatan diri selama hamil antara lain lain keyakinan diri, dukungan sosial dari keluarga, 
pengetahuan dalam merawat kehamilan, akses terhadap pelayanan kesehatan, usia, pendidikan ibu hamil dan suami, status pernikahan, tipe keluarga, pendapatan, dan rencana kehamilan.

\section{Kesimpulan}

Sebagian besar responden memiliki pengetahuan tinggi mengenai tanda bahaya kehamilan dan memiliki perilaku yang kurang tepat dalam merawat kehamilan. Hasil penelitian menunjukkan tidak ada hubungan yang signifikan secara statistik antara pengetahuan tanda bahaya kehamilan dengan perilaku perawatan kehamilan pada ibu hamil trimester III. Meskipun demikian ibu hamil yang berpengetahuan tinggi berpeluang 2,048 kali untuk memiliki perilaku yang tepat dalam perawatan kehamilan.

Saran untuk penyedia pelayanan kesehatan terutama puskesmas adalah agar puskesmas dapat lebih memotivasi ibu untuk merawat kehamilannya dengan lebih baik lagi. Pihak puskesmas juga dapat melibatkan suami atau keluarga untuk berpartisipasi secara aktif dalam mendukung ibu hamil untuk mencapai kesehatan dan kesejahteraannya. Saran untuk penelitian selanjutnya yaitu dapat dilakukan observasi pada komponen perilaku serta meneliti faktor yang mempengaruhi perawatan kehamilan pada masyarakat di Indonesia dengan memperluas tempat penelitian sehingga dapat digeneralisasi (YA, INR, HR).

\section{Referensi}

Badan Perencanaan dan Pembangunan Nasional (BPPN). (2010). Report on the achievement of the Millenium Development Goals Indonesia 2010. Jakarta: Badan Perencanaan dan Pembangunan Nasional.

Bobak, I.M., Lowdermilk, D.L., \& Jensen, M.D. (2005). Buku ajar keperawatan maternitas. (Maria A. Wijayarini, Penerjemah) (Edisi 4). Jakarta: Penerbit Buku Kedokteran EGC. Buku asli diterbitkan tahun 1995.

Celik, Y., \& Hotchkiss, D.R. (2000). The socioeconomic determinants of maternal health care utilization in Turkey. Social Science \& Medicine. 50, 1797-1806.

Chapman, L., \& Durham, R. (2010). Maternalnewborn nursing: The critical components of nursing care. Philadelphia: F.A. Davis Company.

Cole, G.E., Holtgrave, D.R., \& Rios, N.M. (n.d). Internal and external factors that encourage or discourage health-relevant behaviors. Diperoleh dari http://www.orau.gov/cdcyner gy/soc2web/Content/activeinformation/resour ces/Health_Behavior_Factors.pdf.

Dinas Kesehatan Kota Depok. (2008). Tabel profil tahun 2008. Diperoleh dari http://dinkes. depok.go.id/berkas-unggah/tabel\%20profil\% 202008.pdf.

Hailu, M., Gebremariam, A., \& Alemseged, F. (2010). Knowledge about obstetric danger sign among pregnant women in aleta wondo district, Sidama Zone, Southern Ethiophia. Ethiophia Journal Health Science, 20(1), 25-32.

Hastono, S.P. (2006). Analisis data. Depok: Fakultas Kesehatan Masyarakat UI.

Herbert, C.P.(Ed). (1996). Information: usually necessary, but often insufficient to achive behaviour change. Patient Education and Counseling. 29, 229-230.

Kabakyenga, J.K., Ostergren, P.O., Turyakira, E., \& Petterson, K.O. (2011). Knowledge of obstetric danger signs and birth preparedness practices among women in rural Uganda. Reproductive Health, 8 (33). doi:10.1186/ 1742-4755-8-33.

Kristina, S. (2009). Socio-economic \& demographic determinants of maternal health care utilization in Indonesia (Tesis master, Faculty of Social Sciences). The Flinders Univ of South Australia. Diperoleh dari: http://www. itp-bkkbn.org.

Littleton, L.Y., \& Engebretson, J.C. (2009). Maternity nursing care. New York: Delmar Learning.

Mawaddah, N., \& Hardiansyah. (2008). Pengetahuan, sikap, dan praktek gizi serta tingkat konsumsi ibu hamil di Kelurahan 
Kramat Jati dan Kelurahan Ragunan Propinsi DKI Jakarta. Jurnal Gizi \& Pangan, 3 (1), 30-42.

Martin, L.T., McNamara, M.J., Millot, A.S., Halle, T., \& Hair, E.C. (2007). The effects of father involvement during pregnancy on receipt of prenatal care and maternal smoking. Maternal Child Health J, 11 (6), 595-602.

Notoatmodjo, S. (2007). Prinsip-prinsip dasar ilmu kesehatan masyarakat (Edisi 2). Jakarta: Rineka Cipta.

Panthumas, S., Kittipichai, W., Pitikultang, S., \& Chamroonsawasdi, K. (2012). Self-care behaviors among Thai primigravida teenagers. Global Journal of Health Science, 4 (3), 139147.

Pembe, A.B., Urassa, D.P., Carlstedt, A., Lindmark, G., Nyström, L., \& Darj, E. (2009). Rural Tanzanian women's awareness of danger signs of obstetric complications. BMC Pregnancy and Childbirth, 9 (12). doi: 10.1186/1471-2393-9-12.

Pillitteri, A. (2010). Maternal \& child health nursing: Care of the childbearing \& childrearing family. Philadelphia: Lippincott Williams \& Wilkins.

Rashad, W.A., \& Essa, R.M. (2010). Women's Awareness of Danger Sign of Obsetrics Complications. Journal of American Science. 6 (10), 1299-1306.

Sen, E., et al. (2012). Determination of knowledge requirements and health practices of adolescent pregnant women. International Journal of Caring Sciences, 5 (2), 171-178.

Sulistiyowati, N., Ronoatmodjo, S., \& Tarigan, L.H. (2001). Kematian perinatal hubungannya dengan faktor praktek kesehatan ibu selama kehamilan. Jurnal Ekologi Kesehatan, 2 (1), 192-199.

Suryawati, C. (2007). Faktor sosial budaya dalam praktik perawatan kehamilan, persalinan, dan pasca persalinan (Studi di Kecamatan Bangsri Kabupaten Jepara). Jurnal Promosi Kesehatan Indonesia, 2 (1), 21-31.

World Health Organization. (2005). The world health report: Make every mother \& child count. Geneve: WHO Press. Diperoleh dari http:// www.who.int/mediacentre/factsheets/fs348/en/. 